\title{
Genetic analysis of F2 population of tomato for quantitative traits in the cross bushbeef $X$ nagina
}

\begin{abstract}
The purpose of conducting the study was to find the genetic components like $\mathrm{Vg}, \mathrm{Vp}$, GCV, PCV, heritability and Genetic advance in F2 generation of the cross Nagina $\mathrm{x}$ Bushbeef-steak for quantitative traits. Data was collected on P1, P2 F1 and F2 generation for various yield components and analyzed. Analyzed data showed relatively high difference between, GCV and Vp, PCV for the traits: Flowers/cluster, Fruits/cluster and Fruit weight and relatively low difference was noted for Vg, GCV and Vp, PCV value in the traits: Fruit diameter, Fruit length and fruits/plant. Highest value of GCV (79.90\%) and PCV $(92.79 \%)$ were noted in the trait: yield/plant and the lowest values of GCV (14.68\%) and PCV (16.78\%) were noted for fruit-length. Highest value $(84.08 \%)$ of Broad sense heritability \% $(\mathrm{Hb} \%)$ was noted in fruit diameter and the lowest value of heritability(27.58) was noted for the trait fruits/ cluster. Moderate value of heritability (74.13\%) along with low value (15.22) of GA\% was noted for yield/plant
\end{abstract}

Keywords: tomato F2, genetic analysis, heritability, genetic advance, physiological traits, phenotypic co-efficient, quantitative traits
Volume 4 Issue 6 - 2016

\author{
Mehboob Ahmad, Mazhar lqbal, Zishan Gul, \\ Bilal Ahmad Khan, Aneela Kanwal, Maria \\ saleem, Nayyer iqbal Khan \\ Hazara Agricultural Research Station, Pakistan
}

\section{Correspondence: Mehboob Ahmad, Hazara Agricultural Research Station, Abbottabad, Pakistan,} Email mehboob05pbg@yahoo.co.uk

Received: December 23, 2015 | Published: October 26, 2016

\section{Introduction}

Tomato is world's second most important crops after potato where it is consumed in raw form as well as processed form like tomato ketchup or cooked in meal. The fruit is valuable being a contributor of medically important components in our diet like lycopene: an antioxidant which plays important role in prevention of cancer. It is also source of vitamins like vitamin B1, B6, vitamin C and small amount of ascorbic acids. ${ }^{1}$

Intense need is being felt to increase the production of this crop due to increasing world population and consequently increasing consumption. ${ }^{2}$ Like other crops, this crop may also be improved by breeding techniques for the traits like disease tolerance, yield, yield components and shelf life. For any breeding programme it is indispensible to have information about the genetic variability and corresponding heritability as the selection of superior genotypes depends on the degree of genetic variability and extent to which the characters are inherited. ${ }^{3}$ Genetic improvement in the breeding programme depends on the utilization of available or created genetic variability. If the variability in the population is mainly contributed by genetic cause with least environmental effect, the probability of isolating superior genotypes is high. As yield of tomato fruits is a polygenic character and is dependent on many agronomic, morphological and physiological traits, so direct selection for yield may be often misleading. The progress of breeding in such a population is primarily related to magnitude, nature and interaction of genotypic and environmental variation in the various plant characters. ${ }^{4}$ Each of these traits, however, has its own genetic systems. Furthermore, environmental fluctuation affects the yield components. Therefore, it is essential to take apart the total variation into heritable and non-heritable components with the help of genetic parameters i.e genotypic and phenotypic co-efficient of variation, heritability and genetic advance. ${ }^{5}$
Heritability, or the degree of genetic control related to some traits of interest is one of the most important parameters within the breeding research. Heritability determines how much of the phenotypic variability has a genetic origin and how much due to influence of environment, and therefore helps us select on genetic basis. ${ }^{6}$ Genetic advance is another parameter on which effectiveness of selection depends Johnson et al., ${ }^{7}$ For the selection to be effective and for making improvement in the crop, moderate or high heritability should be accompanied by sufficient amount of genetic advance. ${ }^{8}$ The objective of our research is to find the variability related parameters like GCV, PCV Vg and Vp and heritability and genetic advance for yield and yield components. The study will help us in making judicious selection in F2 generation for the desired parameters.

\section{Materials and methods}

\section{Fied data}

The experiment was conducted at Hazara Agricultural Research station Abbottabad during the sowing seasons 2013 to 2015. Crossing was done between two varieties of diverse characteristics Nagina and Bush beefsteak in the month of July 2013.Then F1 seed was collected from the fruits formed through crossing. In the year 2014 F1 seed was sown in the month of April and nursery was transplanted in June 2014. Some F1 seed was reserved for next sowing season.F2 seed was collected from F1 generation and data was also collected. In January 2015 the seed of P1, P2, F1 and F2 were sown in nursery. The plants in nursery were sown in March 2015. Plant to plant distance was kept as $50 \mathrm{~cm}$,row to row distance was kept $100 \mathrm{~cm} .500$ plants of F2 generation were transplanted in three blocks along with $\mathrm{P} 1, \mathrm{P} 2$ and F1 in each block. Data was collected on F2 population and from 5 plants each from P1,P2 and F1 on the parameters : No of flowers/ cluster, No of fruits/cluster, Fruit length $(\mathrm{cm})$, Fruit diameter $(\mathrm{cm})$, Fruit weight(grams), No of fruits/plant and Yield(grams)/plant. 


\section{Statistical analysis}

$\mathrm{Vg}$ (Variance of genotype), Vp (variance of phenotype) and broad sense heritability $(\mathrm{Hb})$ were calculated on MS-excel by using the following formula suggested by Globerson et al. ${ }^{9}$

$$
\mathrm{Hb}=\{\mathrm{VF} 2-[1 / 3(\mathrm{VP} 1+\mathrm{VP} 2+\mathrm{VF} 1)]\} / \mathrm{VF} 2
$$
$\mathrm{Vp}$

Where $\mathrm{Ve}=\mathrm{Vp} 1+\mathrm{Vp} 2+\mathrm{Vf} 1 / 3 \mathrm{Vp}=\mathrm{VF} 2$ and $\mathrm{Vg}=\mathrm{Vp}-\mathrm{Ve}$ So $\mathrm{Hb}=\mathrm{Vg} /$

Phenotypic (PCV) and genotypic (GCV) coefficients of variation were calculated according to the following formula proposed by Singh and Chaudhary. ${ }^{10}$

$$
\begin{aligned}
& P C V=(\sigma p / X) \times 100 \\
& G C V=(\sigma g / X) \times 100
\end{aligned}
$$

Where, $\sigma \mathrm{p}, \sigma \mathrm{g}$, and $\mathrm{X}$ are the phenotypic, genotypic standard deviation and grand mean of the traits respectively.

Expected genetic advance (GA) and percentage of GA were calculated according to following formula proposed by Shukla et al. ${ }^{11}$

Expected genetic Advance $(\mathrm{GA})=\mathrm{i} \sigma \mathrm{ph}^{2}$

\section{Percentage of Genetic Advance $(G A \%)=G A X \times 100$}

Where, i: standardized selection differential, a constant (2.06), $\sigma \mathrm{p}$ : phenotypic standard deviation.

\section{Results and discussion}

The results regarding F2 population of cross combination Nagina $x$ Bush beefsteak for Phenotypic variance $(\mathrm{Vp})$, Genotypic variance (Vg), Genotypic co-efficient of variance (GCV), Phenotypic Coefficient of Variance(PCV),Heritability $\%(\mathrm{Hb})$ and Genetic Advance \%(GA\%) are shown in Table 1. Analyzed data showed that variance of genotype $(\mathrm{Vg})$ was lower than the variance of phenotype $(\mathrm{Vp})$ in the F2 populations for all the traits under study. Same were the findings of Mohamed et al. ${ }^{12}$ and Gosh et al., ${ }^{13}$ except for fruitlength and fruit diameter in his study .In the F2 population higher difference was noted between $\mathrm{Vg}$ and $\mathrm{Vp}$ for the traits Flowers/ cluster, Fruits/cluster, Fruit weight, fruits/plant and Yield/plant while lower difference was found between $\mathrm{Vg}$ and $\mathrm{Vp}$ for the traits like Fruit diameter and Fruit length as shown in Table 1. High difference between $\mathrm{Vg}$ and $\mathrm{Vp}$ indicates that environment has more contribution in the phenotypic appearance of the traits than their genetic make-up.

Relatively higher difference was noted between GCV and PCV values in the traits: Flowers/cluster Fruits/cluster and Fruit weight and relatively low difference was noted for GCV and PCV value in the traits: Fruit diameter, Fruit length and fruits/plant. Khanom et al. ${ }^{4}$ also found smaller difference between GCV and PCV value for the trait fruits/length while Kaushik et al., ${ }^{14}$ found small difference between GCV and PCV for fruit diameter. Moderate difference was noted between GCV and PCV in the parameter yield/plant. Higher difference between GCV and PCV for the traits reveals that the traits are under the influence of environmental effect and non-dominance and non-additive gene actions are involved in the determination of particular traits. Highest value of GCV (79.90\%) and PCV (92.79\%) were noted in the trait: yield/plant which indicates that diversity in the trait is highest than any in other trait. So there is wide range of selection for the breeder. Sivaprasad et al., ${ }^{15}$ also reported high value of GCV and PCV for yield/plant. There is moderate difference between GCV\% and PCV\% for the Yield/plant. Lowest values of GCV (14.68\%) and PCV (16.78\%) were noted for fruit-length which reveals that variation in the trait is lowest than in any other trait so range for selection is narrow. Highest value (84.08\%) of Broad sense heritability \% $(\mathrm{Hb} \%)$ was noted in fruit diameter followed by fruits/ plant and Fruit length i.e. $82.6 \%$ and $76.82 \%$ and, respectively. The results indicate that additive gene action is involved in the traits and influence of environment is less. Lowest value of heritability (27.58) was noted for the trait fruits/cluster. Flowers/cluster and Fruit weight also showed relatively lower value of $\mathrm{Hb}$ i.e. $33 \%$ and $35.17 \%$, respectively.

Table I Variance of genotype $(\mathrm{Vg})$, Variance of phenotype $(\mathrm{Vp})$,Variance of environment (Ve), Genotypic coefficient of variation(GCV), Phenotypic coefficient of

\begin{tabular}{|c|c|c|c|c|c|c|c|c|c|c|}
\hline Parameters & Mean & Range & $\mathbf{V g}$ & Vp & Ve & GCV & PCV & $\mathrm{Hb} \%$ & GA & GA $\%$ \\
\hline Flowers/cluster & 4.18 & 9-Jan & 0.48 & 1.44 & 0.95 & 16.57 & 28.73 & 33 & 0.82 & 19.72 \\
\hline Fruits/cluster & 1.87 & $0-6$ & 0.29 & 1.07 & 0.77 & 29.01 & 55.33 & 27.58 & 0.58 & 31.44 \\
\hline Fruit weight & 63.37 & $20-147$ & 115.71 & 328.91 & 213.2 & 16.97 & 28.61 & 35.17 & 13.14 & 20.73 \\
\hline Fruit diameter & 4.6 & $2.1-6.5$ & 0.53 & 0.63 & 0.1 & 15.82 & 17.26 & 84.08 & 1.37 & 29.89 \\
\hline Fruit length & 4.49 & $2.9-6.53$ & 0.43 & 0.56 & 0.13 & 14.68 & 16.78 & 76.82 & 1.193 & 26.55 \\
\hline fruits/plant & 15.07 & $0-79$ & 89.47 & 108.31 & 18.83 & 62.72 & 69.01 & 82.6 & 17.7 & 117.43 \\
\hline Yield/plant & 930.85 & $0-3010$ & 553205 & 746202 & 192997 & 79.9 & 92.79 & 74.13 & 141.72 & 15.22 \\
\hline
\end{tabular}
variance(PCV), broad-sense heritability $(\mathrm{Hb})$, Expected genetic advance $(\mathrm{GA})$ and Genetic advance percentage (GA \%) for F2 population of cross combination Nagina $x$ Bush beefsteak

GA\% is highest (117.43\%) in fruits/plant among all the traits. was noted for the trait. Our result match with the findings of Saleem The trait has also shown relatively higher value of $\mathrm{Hb} \%$. Our result matched with the findings of Haydar et al. ${ }^{16}$ and Sharanappa et al., ${ }^{17}$ who also found high value of heritability and GA\% for the trait. Lower GA\% for flowers/cluster (19.72\%) fruits/cluster (31.44\%) and fruit weight $(20.73 \%)$ is coupled with lower heritability. The result shows that these traits are under the influence of non-additive gene actions. Mere phenotypic selection for such traits cannot bear any fruitful result in next generation. Moderate value of heritability was found for yield/plant i.e. $74.13 \%$. However, relatively lower GA\% (15.22) et al. ${ }^{18}$ who also found relatively lower value of GA\% (21\%) coupled with low value of heritability $\%$. The traits having high heritability with high genetic advance are deemed to be under control of additive genes, whereas with high heritability and low genetic advance are under the control of non-additive (dominant and/or epistatic) genes which limits the scope of improvement through selection. ${ }^{19}$ Therefore it is suggested that selection for the trait yield/plant in our study on phenotypic basis is not much effective. 


\section{Conclusion}

Yield/plant is most variable traits among other traits however heritability for the trait is moderate with low genetic advance, therefore mere phenotypic selection is not effective. The selection for fruit size traits may be effective due to higher value of heritability.

\section{Acknowledgements}

We are grateful to the scientist of Ayub Agricultural Research Institute Faisalabad, Pakistan for their compliance and provision of germplasm which has enabled us to initiate our breeding programme.

\section{Conflict of interest}

The author declares no conflict of interest.

\section{References}

1. Hasan N, Saeed A, Shakeel A, et al. Genetic analysis to find suitable parents for development of tomato hybrids. Agri For. 2014;60(4):255-265.

2. Ahmad M, Gul Z, Khan ZU, et al. Study of heterosis in different cross combinations of tomato for yield and yield components. Int $J$ Bio. 2015;7(2):12-18.

3. Nechifor B, Filimon R, Szilagyi L. Genetic variability, heritability and expected genetic advance as indices for yield and yield components selection in common bean (phaseolus vulgaris 1.). UASVM Bucharest, Series A: Scientific Papers; 2011. 54 p.

4. Khanom MSR, Khan MHK, Hassan L. Variability, heritability and genetic advance for yield and yield contributing characters in tomato (lycopersicon esculentum mill.). Prog Agri. 2008;19(1):1-5.

5. Maniee M, Kahrizi D, Mohammadi R. Genetic variability of some morpho-physiological traits in durum wheat (Triticum durum). J App Sci. 2009;9(7):1383-1387.

6. Falconer DS. Introduction to quantitative genetics. 2nd ed. Longman, New York, USA; 1981.

7. Johnson HW, Robinson HF, Comstock RE. Estimates of genetic and environmental variability in soya bean. Agro J. 1955;47(7):314-318.
8. Eid MH. Estimation of heritability and genetic advance of yield traits in wheat (Triticum aestivum L.) under drought condition. Int J Gen Mol Bio. 2009;1(7):115-120.

9. Globerson D, Genizi A, Staub JE. Inheritance of seed weight in Cucumis sativus (L.) var. sativus and var. hardwickii (Royle) Kitamura. Theo App Genetics. 1987;74(4):522-526.

10. Singh RK, Chaudhary BD. Biometrical methods in quantitative genetic analysis. New Delhi, India: Kalyani Publisher; 1985. 318 p.

11. Shukla S, Bhargava A, Chatterjee A, et al. Mineral profile and variability in vegetable amaranth (Amaranthus tricolor). Plant Foods Hum Nutr. 2006;61(1):23-28.

12. Mohamed SM, Ali EE, Mohamed TY. Study of heritability and genetic variability among different plant and fruit characters of tomato (Solanum lycopersicon L.). Int J Sci Tech Res. 2012;1(2):55-58.

13. Ghosh KP, Islam AK, Mian MAK, et al. Variability and character association in F2 segregating population of different commercial hybrids of tomato (Solanum lycopersicum L.). J App Sci Enviro Manag. 2010;14(2):91-95.

14. Kaushik S K, Tomar DS, Dixit AK. Genetics of fruit yield and it's contributing characters in tomato (Solanum lycopersicom). J Agri Biotech Sus Dev. 2011;3(10):209-213.

15. Sivaprasad K, Sridevi O, Salimath PM. Genetic variability studies in biparental mating populations of tomato (Solanum lycopersicon (Mill) Wettsd.). Ind J Crop Sci. 2009;4(1\&2):121-125.

16. Haydar A, Mandal MA, Ahmed MB, et al. Studies on genetic variability and interrelationship among the different traits in tomato. Mid East J Sci Res. 2007;2 (3-4):139-142.

17. Sharanappa KP, Mogali SC. Studies on genetic variability, heritability and genetic advance for yield and yield components in F2 segregating population of tomato (Solanum lycopersicon L.). Karnatak J Agri Sci. 2014;27 (4):524-525.

18. Saleem M Y, Asghar M, Iqbal Q. Analysis of Genetic Proximity in Tomato (Solanum lycopersicum L.) Genotypes. J Enviro Agri Sci. 2015;3:8-13.

19. Akbar M, Mahmood T, Yaqub M, et al. Variability, correlation and path coefficient studies in summer mustard (Brassica juncea L.). Asian J Plant Sci. 2003;2(9):696-698. 